\title{
A lei n. 5.692/71 e a obrigatoriedade da educação artística nas escolas: passados quarenta anos, prestando contas ao presente
}

\author{
Maria José Dozza Subtil*
}

\begin{abstract}
Resumo:
Analisa-se a lei n. 5.692/71 na instituição da obrigatoriedade da educação artística, explicitando seus fundamentos teóricometodológicos e problematizando-a por meio de pesquisa em documentos legais, artigos, livros didáticos e projetos de trabalho. Fundamentos do materialismo histórico e dialético subsidiam a análise histórica no contexto externo e interno à escola, com suporte das categorias totalidade e contradição, além do recurso à história das disciplinas. Afirma-se que os encaminhamentos metodológicos propunham a adequação da escola, dos professores e da disciplina a um projeto tecnicista de desenvolvimento econômico e controle da realidade social. Autores são chamados para refletir sobre os fundamentos da lei e sua permanência ainda hoje na realidade escolar.
\end{abstract}

\section{Palavras-chave:}

políticas educacionais; lei n. 5.692/71; educação artística; ensino de arte; polivalência.

* Mestrado em Educação, Universidade Estadual de Ponta Grossa (UEPG). Doutorado em Engenharia de Produção, Mídia e conhecimento Universidade Federal de Santa Catarina (UFSC). 


\title{
Law n. 5692/71 and the obligation of arts education in schools: forty years passed, reporting to the present
}

\author{
Maria José Dozza Subtil
}

\begin{abstract}
:
This study analyzes law n. 5.692/71 in establishing the obligation of Arts Education clarifying its theoretical and methodological basics and questioning it by searching legal documents, articles, textbooks and work projects. Basics of historical and dialectical materialism subsidize the historical analysis in the external and internal school context, supported by the categories of totality and contradiction, besides the resource to History of the subjects. It is said that methodological referrals have proposed the school, teachers, and subject's suitability under a technicist project of economical development and social reality control. Authors are requested to reflect on the Law basics and its persistence still today in school reality.
\end{abstract}

\section{Keywords:}

educational policies; law n. 5692/71; arts education; arts teaching; versatility. 


\section{Introdução}

A LDB 9.394/96 (BRASIL, 1996), ao definir a obrigatoriedade do “ensino de arte" em lugar de "educação artística" revela o resultado dos debates das últimas décadas quanto à especificidade de cada área: música, teatro, artes visuais e dança. Na sequência, a lei n. 11.769/2008 (BRASIL, 2008) modifica a anterior e torna obrigatório o ensino de música, delimitando ainda mais o campo artístico.

Esses encaminhamentos legais são o corolário da dialética afirmação/ negação da lei n. 5.692/71 (BRASIL, 1971). No primeiro pressuposto, ao reforçar a obrigatoriedade para o ensino de arte; no segundo, ao contrapor a especificidade de cada campo à polivalência ou integração dos campos da arte não só entre si, mas também com o campo mais abrangente da comunicação e expressão, apregoados por essa lei.

Em 2011, a lei n. 5.692/71 completou 40 anos de promulgação no contexto autoritário do golpe militar que, contraditoriamente, ou talvez nem tanto, como veremos a seguir, propôs a obrigatoriedade da educação artística no ensino de $1^{\circ}$ e $2^{\circ}$ graus, por meio do artigo $7^{\circ}$.

Analisando através do tempo, é possível indagar como e porque, num contexto autoritário, que excluía a reflexão filosófica e política, que impedia a livre manifestação e expressão, que encarcerava, torturava e extraditava seus artistas, ao mesmo tempo tornava obrigatória a "educação artística" nas escolas?

Uma das hipóteses seria a de que a arte, uma área historicamente ligada ao exercício da liberdade e da expressão criadora, deveria manter-se sob controle, tornar-se um instrumento a favor da conservação e dos objetivos desenvolvimentistas apregoados pela ditadura militar. Evidentemente, a obrigatoriedade da educação artística veio revestida de um discurso centrado no desenvolvimento individual dos educandos, embasada num caráter técnicocientífico e com um planejamento rigoroso que escamoteava a crítica e a contradição.

Pode-se perguntar a essa altura, passados quarenta anos: qual a importância de trazer à tona essas questões? Por que revolver uma situação já superada por outras leis e outras práticas artísticas no interior da escola?

Parte-se do princípio de que as práticas escolares atuais resultam de concepções teóricas e encaminhamentos legais que se afirmaram e resistem às 
possibilidades de mudanças (SUBTIL, 2009a, b; 2011; STORI, 2011). Objetivase entender como a arte se disciplinarizou (CHERVEL, 1990), considerando o embasamento do materialismo histórico e dialético na problematização das injunções políticas e econômicas desse momento, tendo em perspectiva a totalidade e a contradição como categorias fundantes nessa compreensão.

A proposta é retornar à lei através dos documentos explicitadores dos seus fundamentos, os teóricos que os embasaram, as publicações, os livros didáticos e os registros da uma prática de aplicação desses fundamentos legais, numa dada realidade, no Paraná na década de 1970. No intento de prestar contas ao presente de um passado não muito distante na história da educação brasileira, também são utilizados autores que explicam e fazem a crítica aos fundamentos e objetivos dessa lei.

O texto não pretende abarcar a totalidade da problematização aqui suscitada, mas fazer a exegese dos intervenientes que encaminharam uma determinada feição didático-pedagógica à arte e que se refletem hoje no campo escolar. Objetiva-se com esse trabalho:

- apresentar aportes teóricos e históricos da disciplinarização da arte na escola, num determinado período da história da educação brasileira - particularmente a década de 1970;

- apresentar os fundamentos teóricos e metodológicos gerais que informaram a lei n. 5.692/71, seus determinantes mais amplos e as interpretações didático-pedagógicas para o ensino de arte, presentes em publicações e livros didáticos;

- propor uma revisão crítica dos fundamentos e propósitos da lei n. 5.692/71 para a educação artística.

\section{Aportes teóricos sobre a disciplinarização da arte}

Para Forquin (1992), é importante obter informações sobre a seleção cultural feita pela escola, identificando o que é privilegiado para ser ensinado num determinado tempo histórico, buscando pistas para analisar as complexas relações entre escola e sociedade, do ponto de vista interno. O autor enfatiza como as escolas tanto refletem como refratam as definições da sociedade acerca da validade de certos conhecimentos culturais. 
Já o termo disciplina, no sentido de conteúdos de ensino, segundo Chervel (1990), só aparece mais recentemente — nas primeiras décadas do século XX -, podendo se identificar a atitudes repressivas ou ainda relativo ao verbo disciplinar, que é sinônimo de exercício intelectual. Os termos que equivaleriam à disciplina, durante o século XIX, como conteúdos de ensino, eram: objetos, partes, ramos ou ainda matérias de ensino. Na visão do autor, o termo disciplina está vinculado à ideia de hierarquização e estratificação.

Numa perspectiva sociológica, a hipótese central na nova sociologia da educação é a de que

[...] o modo como uma sociedade seleciona, classifica, distribui, transmite e avalia os saberes destinados ao ensino, reflete a distribuição do poder em seu interior e a maneira pela qual aí se encontra assegurado o controle social dos comportamentos individuais (BERNSTEIN, 1975 apud FORQUIN, 1992, p. 39).

Nós acrescentaríamos que, no caso em estudo, a disciplina educação artística também objetivou o controle social.

Souza Júnior e Galvão (2005) estudam a constituição das disciplinas educação física e educação artística e afirmam a especificidade e mesmo a novidade desses campos nas escolas. Segundo eles, esses conhecimentos “[...] lidam com o corpo e a sensibilidade [...] e se referem a áreas da atividade humana que não constituem, fora da escola, a não ser muito recentemente, saberes propriamente científicos, com uma tradição epistemológica de longa data". Os autores, analisando a ideia de "[...] transposição didática [...]"1 do artístico para o pedagógico, mostram as “[...] fragilidades para compreender esse tipo de disciplina [...]” (SOUZA JÚNIOR; GALVÃO, 2005, p. 12).

Concordamos com eles já que a especificidade da arte frente às demais disciplinas deve-se ao aporte das capacidades imaginativas, intuitivas e do intercurso da emoção na relação sujeito-objeto, mesmo não abdicando da técnica e da ciência.

No Brasil, a inserção da arte no campo pedagógico decorre da herança humanista europeia, cuja gênese provavelmente está nas matérias literárias

1 Essa transposição supõe um trabalho didático-metodológico para criar um saber escolarizado adequado à transmissão de conhecimentos testados e instituídos num dado campo científico, conforme Chervel (1990). 
- o trivium da Alta Antiguidade e da Idade Média (FORQUIN, 1992) da visão pragmatista norte-americana evidenciada no escolanovismo, além da marcante tendência tecnicista da reforma na Lei 5.692/71.

A obrigatoriedade da educação artística, para além das injunções ideológicas e legais, foi, de início, motivo de comemoração entre os educadores, porque atendia a demandas da área por valorização desse ensino além de contemplar o resultado de debates teóricos sobre criatividade e livre expressão. No entanto, não colocou em pauta as propostas de artistas e movimentos artísticos que se envolveram numa arte mais engajada².

Essa contradição é reafirmada por Silva (2004 apud SOUZA JÚNIOR; GALVÃO, 2005 p. 405):

[...] embora a Arte esteja presente no currículo escolar brasileiro desde o século XIX - com outras denominações e, em alguns casos, no interior de outras disciplinas —, é somente durante a ditadura militar (a partir da lei n. 5.692/71) que esta vira disciplina escolar obrigatória — com a denominação de Educação Artística.

O próximo item mostra que, desde a década de 1920, ganhavam força, na sociedade brasileira, movimentos pró-arte e cultura como impulsionadores da implantação da arte na escola. Assim, a "transposição didática" da arte já se encontrava em processo de encaminhamento pelo aporte dos estudos da Psicologia da criança, decorrentes, dentre outros fatores, do escolanovismo.

\section{Antecedentes históricos da institucionalização do ensino de arte}

A Semana de Arte Moderna em 1922 significou renovação cultural e um movimento emblemático de vanguarda. Marcante, nesse período, foi

2 É importante ressaltar que, nesse período, houve proibição de ações dos Centros Populares de Cultura (CPC), de artistas, escritores e produtores como Augusto Boal e Jeanfrancesco Guarnieri, para falar somente do teatro. Então, na verdade, cabe ressaltar que as concepções que norteavam a lei não consideraram o caráter mais denso, crítico e revolucionário da arte e de outros temas que faziam parte das discussões e produções das décadas de 1960 e 1970. 
o envolvimento de artistas de várias modalidades: artes plásticas, música, pintura, poesia, dança, que, a despeito de reações conservadoras de alguns setores, promoveram mudanças substanciais no panorama da cultura brasileira nos anos 1920 e 1930 (MAIA, 2000).

Na esteira dessas mudanças, a educação sofreu influência das pesquisas psicológicas divulgadas por psicólogos e educadores norte-americanos, que desviavam o foco da transmissão do saber para o interesse dos sujeitos em aprender e operar. Tais aportes marcaram o debate sobre a educação em geral e o ensino de arte em particular.

No ensino de arte, dentro dessa concepção derivada da pedagogia renovada, apregoava-se a substituição da cópia pela livre expressão e, da reprodução das obras, passou-se à criação e experimentação ${ }^{3}$. Nesse sentido, foi de fundamental importância o livro Art as experience de Dewey que, apropriado pelos educadores escolanovistas, tornou-se um dos pilares das propostas de educação para as crianças. Há o entendimento de que as concepções e práticas de ensino de arte, a partir dessa perspectiva, se afirmaram com tendências teórico-metodológicas sustentadas pela estética modernista e pelos aportes dos métodos ativos da Escola Nova de forma definitiva (PARANÁ, 1988).

$\mathrm{Na}$ década de 1930, Villa-Lobos assentou as raízes de sua música na tradição folclórica e popular e idealizou o projeto do canto orfeônico, como ensino de canto coral (orfeão) para as escolas brasileiras, fundamentado na teoria musical. A ênfase desse compositor no folclore e a exaltação do civismo nas grandes concentrações mereceram críticas pela suposta aproximação aos movimentos do extremo nacionalismo europeu. É necessário afirmar, ao menos para fazer um contraponto, que os artistas do movimento artístico modernista das décadas de 1920 e 1930 propunham resistência à dominação estrangeira e buscavam as características nacionais da arte brasileira, submetida desde meados do século XIX, aos cânones do neoclassicismo e da arte decorativa (MAIA, 2000).

Na década de 1940, após a queda do regime ditatorial, houve um período de intenso desenvolvimento cultural e artístico com a inauguração,

3 O currículo básico do Paraná (1990) explicita a perspectiva tradicional no ensino de arte como uma aproximação o mais perfeita possível às grandes obras. Assim, por exemplo, na pintura, apregoava-se a cópia das obras e a reprodução de objetos do ponto de vista clássico (perspectiva) e, na música, o estudo da teoria musical. 
em 1947-1948, de três museus de importância: o MASP (Museu de Arte de São Paulo), o MAM (Museu de Arte Moderna) e o Museu de Arte do Rio de Janeiro. Essa efervescência cultural teve reflexos na educação para a arte, e os ideais escolanovistas vieram novamente à tona (BARBOSA, 1985).

$\mathrm{O}$ artista Augusto Rodrigues criou a "Escolinha de Arte do Brasil" em 1948, tendo como princípio básico a livre expressão criadora, “[...] o que foi recebido com grande entusiasmo pelos educadores envolvidos no processo de revitalização educacional como Anísio Teixeira e Helena Antipoff [...]" (BARBOSA, 1985, p. 15). Destaque-se que as escolinhas de arte "[...] até 1973 eram os únicos espaços não só para o aperfeiçoamento dos arte-educadores como também para o ensino da arte [...]" (PARANÁ, 1988, p. 118).

A partir de meados da década de 1960 articulou-se a tendência tecnicista na educação brasileira em decorrência do modelo socioeconômico desenvolvimentista que começava a se implantar no Brasil. Nesse momento, o golpe militar estabelece condições para a implementação do mercado de consumo e a industrialização sob a hegemonia norte-americana, cujos técnicos impulsionaram e organizaram a reforma da educação brasileira. As concepções dessa reforma afirmam os interesses da sociedade industrial, que considera como função prioritária da escola o preparo técnico das aptidões para o trabalho e para o mercado consumidor.

Analisando a lei n. 5.692/71 numa perspectiva estrutural, Saviani (1997, p. 38) afirma:

Com efeito, os princípios de não-duplicação de meios para fins idênticos com seus corolários, tais como a integração ( vertical e horizontal), a racionalização-concentração, a inter complementaridade, a flexibilidade, a continuidade-terminalidade $[. .$.$] indicam$ uma preocupação com o aprimoramento técnico, com a eficiência e produtividade em busca do máximo de resultados com o mínimo de dispêndio.

No que se refere ao campo do ensino de arte de modo geral, nesse momento, vigoram cânones tradicionais de desenho, as ideias da livre expressão exercitadas nas escolinhas de artes, alguns aportes dos métodos da educação musical decorrentes da Escola Nova e as comemorações das datas cívicas e folclóricas.

Como veremos no próximo item, a forma como a arte foi disciplinarizada não permite o uso, mesmo com moderação e resguardando os devidos limites 
teóricos, do conceito de "transposição didática" que respeitaria pelo menos os conhecimentos próprios da área.

\section{A lei n. 5.692/71 - imperativos legais, fundamentos teórico-metodológicos, interpretações ... e a prática}

Os determinantes legais para a implantação da educação artística ${ }^{4}$

O artigo $7^{\circ}$ da lei n. 5.692 diz: "Será obrigatória a inclusão de Educação Moral e Cívica, Educação Física, Educação Artística e Programas de Saúde nos currículos plenos dos estabelecimentos de $1^{\circ}$ e $2^{\circ}$ graus [... $]^{\prime 5}$ (RIO DE JANEIRO, 1977a, p. 49). A inclusão da educação artística no núcleo comum objetiva

[...] promover o alcance do objetivo geral do ensino de $1^{\circ}$ e $2^{\circ}$ graus: "proporcionar ao educando a formação necessária ao desenvolvimento de suas potencialidades como elemento de auto-realização, qualificação para o trabalho e preparo para o exercício consciente da cidadania" (RIO DE JANEIRO, 1977a, p. 49).

O Documento I (A educação artística e os documentos legais), diz em sua apresentação:

4 A análise aqui efetuada baseia-se de modo geral em dois documentos que encaminham interpretações e orientações sobre a implantação da educação artística no ensino de $1^{\circ} \mathrm{e}$ $2^{\circ}$ graus da rede municipal do Rio de Janeiro a partir do artigo $7^{\circ}$ da lei, e da resolução n. 8, de dezembro de 1971 (Anexa ao parecer 853/71 do CFE), do parecer 820/72 e dos fundamentos teóricos que embasavam esses textos. Optamos por utilizar esses documentos mais do que as fontes legais porque eles já contemplam a interpretação e as orientações de caráter pedagógico, ou seja, configuram a gestão da lei numa dada realidade. Serão nomeados Documento I - A educação artística e os documentos legais (RIO DE JANEIRO, 1977a) - e Documento II - Arte na escola de $1^{\circ}$ grau (RIO DE JANEIRO, 1977b).

5 A denominação $1^{\circ}$ grau $\left(1^{\mathrm{a}}\right.$ a $8^{\mathrm{a}}$ série $)$ e $2^{\circ}$ grau corresponde ao que hoje se denomina educação básica em seus segmentos ensino fundamental e ensino médio. 
As Unidades Temáticas deste trabalho são as mesmas para os professores de Artes Cênicas, Artes Plásticas e Educação Musical em face da legislação em vigor que recomenda: "o professor do ensino de $1^{\circ}$ grau não tem de ser um especialista em determinadas divisões da Arte" mas "perceber o fato artístico na substancial unidade que reveste em meio às suas distintas manifestações[...]”. (RIO DE JANEIRO, 1977a, p. 13).

Cabe aqui uma tomada de posição em relação à validade de uma concepção integradora das áreas artísticas no ensino de arte, para além do reducionismo dessa polivalência proposta na lei, se entendemos que existe sim um caráter de unidade na produção e fruição do objeto artístico, seja ele em que área for. Essa unidade reside na vinculação da arte ao contexto histórico e social. Nesse sentido, para Canclini (1984, p. 3), deve-se analisar a arte como um processo social e comunicacional, inserido numa dada sociedade e num determinado tempo histórico. $\mathrm{O}$ autor apregoa uma visão menos fragmentada de arte: "[...] como é possível que os alunos de música ignorem durante toda a sua carreira aquilo que os alunos de artes-visuais estudam, e estes, a música, em meio a um desenvolvimento cada vez mais impressionante dos meios audiovisuais?" (CANCLINI, 1984, p. 9).

No entanto, as condições políticas, sociais e econômicas da formulação da lei não deram conta desse fundamento e a desconsideração da formação específica revelou-se problemática, como a história bem demonstrou na sequência.

No documento analisado, as Bases conceituais da educação artística enfatizam questões sobre criatividade: definir criatividade; aplicar na escola o conceito de criatividade; aplicar o conceito de criatividade em situações de vida; identificar o pensamento convergente e o divergente; relacionar criatividade/arte/educação. Também estabelece a relação entre arte $e$ educação como vantagem para esta última, ou seja, o valor pedagógico da arte não está aferido ao seu conteúdo, mas à vinculação a um objetivo geral da lei, que é a formação integral do aluno, em especial como formação da expressão criadora, capaz de

[...] prover o aluno com experiências ricas e com encontros que lhe permitam lidar com a fantasia, ser imaginativo, fazendo perguntas, maravilhando-se, investigando e testando suas próprias idéias e sentimentos, contra os fatos (sic) que permitirão aos indivíduos progredir por si mesmos, de modo consciente, num estilo de aprendizagem. (RIO DE JANEIRO, 1977a, p. 47-48). 
Justificando a amplitude dos objetivos da lei, sem ultrapassar os limites impostos pela ideologia da ditadura militar, veja-se o sentido de "social" apregoado:

Para todos é acentuado o duplo aspecto, individual e social, que convém a uma educação democrática, indicada pelos fatores: auto-realização (aspecto individual), qualificação para o trabalho (duplo aspecto individual e social) e cidadania consciente (aspecto social) [...]. (RIO DE JANEIRO, 1977a, p. 60, grifo no original).

Ao situar a educação artística no contexto das matérias integrantes do conteúdo comum assim definido: "Núcleo comum + artigo 7"o", o Documento I propõe a metodologia de integração não só entre as diferentes linguagens da arte, mas no contexto das atividades e experiências de caráter geral, concretas e progressivas, próprias das primeiras séries, dentro da perspectiva da Psicologia Genética, como veremos adiante quando procederemos à crítica aos fundamentos da lei.

O Documento I apresenta na íntegra o artigo $4^{\circ}$ da resolução $\mathrm{n}^{\circ} 8$ de $1^{\circ}$ de dezembro de 1971:

Parágrafo $1^{\circ}$ - Nas atividades, a aprendizagem far-se-á principalmente mediante experiências vividas pelo próprio educando no sentido de que atinja, gradativamente, a sistematização dos conhecimentos.

Parágrafo $2^{\circ}$ - Nas áreas de estudos, formadas pela integração de conteúdos afins, as situações de experiência tenderão a equilibrar-se com os conhecimentos sistemáticos para configuração da aprendizagem.

Parágrafo $3^{\circ}$ - Nas disciplinas, a aprendizagem se desenvolverá predominantemente, sobre conhecimentos sistemáticos. (RIO DE JANEIRO, 1977a, p. 66).

Aqui se afirma a gradualização metodológica prevista pela lei. Cabe considerar o encaminhamento das matérias na forma acima configurada de modo a atender não só aos propósitos da Psicologia do desenvolvimento, mas também a questões de nível didático: “[...] não há uma relação necessária entre o nível de escolaridade e o modo de tratar as matérias [...], já que mesmo no $2^{\circ} \mathrm{Grau}$ algumas disciplinas das habilitações profissionais podem merecer $\mathrm{o}$ tratamento de atividades [...]" (RIO DE JANEIRO, 1977a, p. 67). 
As formulações do Documento I dão conta de que a lei deixa à escola a escolha dos conteúdos e estratégias e "Confia ao professor, [...] a tomada de decisões sobre as estratégias e táticas que serão utilizadas no desenvolvimento de seus programas [...]" (RIO DE JANEIRO, 1977a, p. 71).

Cabe considerar o reforço do documento em questão ao enfoque psicológico quando alerta: "Os procedimentos didáticos adotados pelos professores, por sua vez, acompanharão a fase do desenvolvimento em que se encontra o aluno [...]". (RIO DE JANEIRO, 1977a, p. 76), mencionando o parecer 853/71 e especificamente a psicologia genética de Jean Piaget, como fundamento para sua compreensão. Importa afirmar que, apesar dessa referência, no cômputo geral, o que prevalece é a submissão dos conhecimentos à técnica de relacionamento, ordenação e sequência calcada na dimensão tecnicista.

Como corolário dos encaminhamentos da lei n. 5.692/71, uma questão que afeta o ensino de arte até os dias de hoje é a da “[...] concepção integradora do núcleo-comum [...] situado 'na perspectiva de todo conhecimento humano encarado em suas grandes linhas', a partir do mais geral para o mais específico [...]'.(RIO DE JANEIRO, 1977a, p. 72, grifo no original).

Essa integração coloca a arte dentro da área de comunicação e expressão e isso prevalecerá no senso comum escolar. Pesquisa realizada (SUBTIL, 2009a) mostra que, nos segmentos finais do ensino fundamental, antes chamados de $5^{\mathrm{a}}$ a $8^{\mathrm{a}}$ séries, os professores de língua portuguesa são maioria no ensino de artes (nas áreas de estudo). O Documento I informa sobre a pertinência de um professor único nas séries iniciais para chegar ao das áreas de estudo no restante das séries do $1^{\circ}$ grau e complementa:

[...] é de se supor que ainda se tenham mestres à parte somente para Educação Física e Educação Artística, embora esta última se inclua razoavelmente em Comunicação e Expressão, conforme as qualidades pessoais e de formação de quem a ministre (RIO DE JANEIRO, 1977a, p. 82, grifo nosso).

Eis aí configurados não só o enfoque integrador que a área assume nos currículos como também o perfil do profissional que vai atuar. Em decorrência, aparece explicitada no Documento II a função desse profissional: "O professor de arte é, antes de tudo, um dinamizador. Cabe a ele a função de ativar e manter em ação o processo perceptivo-operatório daqueles que estão 
iniciando ou vão desenvolver habilidades artísticas [...]" (RIO DE JANEIRO, 1977b, p. 83). Na sequência, pretende-se aprofundar a reflexão sobre esses fundamentos teórico-metodológicos para o ensino de arte.

Os fundamentos teóricos e encaminhamentos metodológicos da lei n. 5.69271

O Documento II (A arte na escola de $1^{\circ}$ grau) explicita com mais detalhes algumas concepções sobre os fundamentos metodológicos da educação artística. Já nos objetivos do módulo que se destinava ao "Desenvolvimento de recursos humanos" aparecem algumas pistas da metodologia privilegiada para a educação artística no contexto da lei:

Reconhecer a importância do processo sobre o produto na avaliação do desenvolvimento do aluno; [...] Relacionar a Educação Artística aos fatores de desenvolvimento do aluno e sua avaliação; Justificar a necessidade de integração da Educação Artística com as demais disciplinas do currículo [...] (RIO DE JANEIRO, 1977b, p. 15).

As formulações do Documento II apontam para a valoração da atividade do aluno independente do resultado, na perspectiva dos centros de interesse apregoados pela Escola Nova; o desenvolvimento integral do aluno fundamentado na psicologia genética de Piaget; e a reafirmação da integração com outras disciplinas do currículo para além da polivalência na área (RIO DE JANEIRO, 1977b).

Dois pontos encaminham o entendimento dos fundamentos subjacentes ao documento. O primeiro são as discussões sobre comunicação, presentes nos espaços culturais e educacionais embasados nos escritos de Mac Luhan que, já no final da década de 1960, teorizava sobre uma nova era nas relações comunicacionais $^{6}$, cujo mote mais conhecido era $O$ meio é a mensagem ${ }^{7}$

6 McLuhan, M. Os meios de comunicação como extensões do homem. 5. ed. São Paulo: Cultrix, 1989.

7 McLuhan, H.M.; Fiore, Q. The Medium is the Massage: An Inventory of Effects. New York: Bantam Books, 1967. 
para designar a relação de igualdade entre mensagens e meios (tecnologias). O segundo é o uso do mote tecnológico e sistêmico inputs e out-puts, que definiam a organização dos objetivos instrucionais e comportamentais (entrada e saída) como ordenadores das práticas pedagógicas.

O texto faz também referência à difícil situação econômica do país e aponta para a necessidade de buscar alternativas de materiais na própria comunidade, como forma de transformar a escola em ambiente adequado ao trabalho criativo ${ }^{8}$.

No Documento II, Ana Mae Barbosa já apresenta algumas críticas, que seriam acentuadas nas próximas décadas, ao modo de fazer arte proposto pela lei n. 5.692/71: a ênfase no processo e não no produto (ela iguala os dois polos), associada à falta de especificidade dos conteúdos da arte (RIO DE JANEIRO, 1977b, p. 45-46). Cabe registrar as expressões arte/educação e arte/educador em seus escritos, que serão apropriadas pelo campo artístico e caracterizarão as discussões sobre ensino de arte até a década de 1990.

A autora mencionada faz referência aos teóricos da criatividade mais em voga naquele momento: Torrance, Brunner, Hugh Lytton e Guilford, entre outros, para afirmar a arte-educação na escola a partir do foco das artes visuais. Esse foi um dos problemas enfrentados pelas outras áreas de arte, que seguiram a reboque desses conceitos destinados ao desenvolvimento da percepção visual, ao trabalho com imagens, etc.

No que se refere à avaliação, o Documento II apresenta uma reflexão sobre a aprendizagem: "Os novos processos desenvolveram-se de uma psicologia da aprendizagem mais atualizada, que acentua a modificação do comportamento, o crescimento contínuo, as aprendizagens múltiplas e a compreensão" (RIO DE JANEIRO, 1977b, p. 71).

Em seguida, coloca o sentido de avaliação: “[...] avaliação diz respeito não apenas à matéria aprendida, mas a atitudes, interesses, hábitos de trabalho, desenvolvimento físico e, também, ajustamento pessoal-social" (grifo nosso).

Aqui aparece clara a contradição, já apontada por Ana Mae, entre a ênfase no desenvolvimento da criatividade e na promoção de um "[...] jovem convencional, bem ajustado e socialmente bem-sucedido [...]" (RIO DE JANEIRO, 1977b, p. 42). A coerência da lei está justamente em afirmar

8 Pode-se inferir que daí decorrem as experiências com sucata, na maioria das vezes malsucedidas, que durante muitos anos foram apregoadas como estratégia de desenvolvimento da criatividade nas escolas. 
o que o momento político exigia: mais ajustamento social e conformidade aos valores cívicos da ditadura do que propriamente um espírito criador.

Em arte, obviamente, se entendia que a avaliação deveria circunscreverse ao desenvolvimento de atitudes, de interesses e da expressão criadora: "Professores e diretores de escolas de $1^{\circ}$ Grau estão se compenetrando cada vez mais da responsabilidade de fomentar a auto-expressão criadora dos alunos [...]" (RIO DE JANEIRO, 1977b, p. 77, grifo nosso). Essa seria uma condição para a formação de indivíduos criadores na forma de tratar as pessoas, situações, problemas e materiais, ajustado a uma genérica "complexa sociedade contemporânea” (RIO DE JANEIRO, 1977b, p. 77).

O que aparece nessas formulações é a emergência da criatividade como o aparato teórico-pedagógico para formar os alunos. O discurso perpassa todas as áreas do currículo e, nessa perspectiva, as estratégias de avaliação não podem ser formais, uma vez que essa capacidade é considerada "pelas normas próprias da criança" (RIO DE JANEIRO, 1977b, p. 77). Evidencia-se a centralidade da criança, o enfoque comportamentalista e a tendência tecnicista.

Do ponto de vista da história das disciplinas, Chervel (1990) considera que é fundamental o estudo da "vulgata", o conjunto de escritos, normas, diretrizes, manuais, periódicos que traduzem a organização do corpus de conhecimentos da disciplina, seus fundamentos e metodologias, como condição para a compreensão mais abalizada da constituição desse campo dentro da escola. Essa é a pretensão do próximo item.

\section{A aplicação dos pressupostos teóricos e metodológicos da lei}

\section{Publicações e livros didáticos}

Chevallard (1985 apud CHERVEL, 1990, p. 185), ao definir a transposição didática, faz referência ao papel das publicações nesse processo:

Da escolha do saber a ensinar à sua adaptação ao sistema didático, existe todo um processo gerador de deformações, de estabelecimento de coerência e até de criação de novos conhecimentos, que culmina com o que se chama de saber escolar, enunciado nos programas e, particularmente, observáveis nos livros-texto. 
Quanto às publicações que interpretavam a educação artística e faziam sugestões em relação à sua aplicabilidade na escola, tomamos como exemplo a Revista Brasileira de Estudos Pedagógicos - RBEP (1973), que, entendemos, disseminava o pensamento pedagógico institucional da época. Chamamos a atenção para a ênfase às artes plásticas em detrimento das artes cênicas e da educação musical.

Os títulos dos capítulos trazem temas como: Artes plásticas na escolauma experiência; Programa de educação artística: artes plásticas no $1^{\circ}$ grau. Os temas gerais apresentados - Arte infantil, Educação criadora, Atividades artísticas com fins terapêuticos e educativos, entre outros - também abordam atividades de artes plásticas, com algumas menções à dança e ao teatro mas nenhuma à música.

Os autores privilegiados, a maioria estrangeiros, como Dewey, Arenheim, Read, McLuan, H. Stern, Kneller, Lowenfeld, Freud, e as ideias que circulam nesse momento enfatizam as artes plásticas, a comunicação e expressão e teorias da criatividade como fator de autodesenvolvimento. Isso decorre, como já afirmamos, em grande parte, das experiências criadoras e expressivas das escolinhas de artes e das temáticas aí discutidas e postas em prática.

Afirma-se em determinado momento: "Acreditamos que a área de Expressão Artística compreende: jogos de expressão, expressão musical e expressão plástica [...]" (REVISTA..., 1973, p. 617). Entendida a expressão musical como: “[...] criar através da música situações, representando com sons os materiais (papel, concreto, vidro, pão...), o vento etc. e desenhar inspirando-se no som [...]" (REVISTA..., 1973, p. 616).

Subtil (2009b), ao analisar publicações e livros didáticos da época, constata que, mesmo como atividade, a música tem pequena inserção nesses documentos e aparece citada como jogos de expressão musical, evidenciando sua submissão à expressão pelas artes plásticas. Da mesma forma, a ideia de criação estava ligada às atividades plásticas e ao teatro como jogo dramático na perspectiva lúdica. Pode-se dizer que o campo da educação artística se instituía pela hegemonia das artes plásticas, sinônimo de arte-educação na escola.

Os livros didáticos estavam, em sua maioria, de acordo com as perspectivas tecnicistas e polivalentes que a lei apregoava. Os títulos, tomados como exemplos, são reveladores: Integrando as artes (ABRAHÃO, 1977); Comunicação pela arte - Educação artística (FLEITAS, 1977); Música e comunicação (ABRAHÃO, s./d.); Comunicação pela arte (1977); Caderno 
de desenho - Educação artística (HERLING, s./d.); Comunicação visual e expressão (PENTEADO, 1977); Educação artística - expressão corporal, musical e plástica (COTRIM, 1978).

A maioria apresenta o livro do professor e o caderno de atividades para os alunos. As orientações didáticas aparecem na forma de "estudo dirigido" e estabelecem uma comunicação direta com o aluno. Muitas dessas publicações trazem mais de um volume, destinado a cada ano, da $5^{\mathrm{a}}$ à $8^{\mathrm{a}}$ séries. Propõem exercícios com elementos das artes visuais (cores, ponto e linha, técnicas de pintura, colagem, montagem com materiais). O teatro aparece em menor grau, através de algumas definições, história e sugestões de atividades. Em música, são apresentados os gêneros e formas musicais, hinos e canções folclóricas com as respectivas partituras e teoria musical. Muitos livros contêm exercícios e conteúdos de desenho geométrico integrados às atividades de educação artística. Na verdade, não há muita delimitação entre essas duas áreas.

Dentro de uma perspectiva dialética, não é negada a possibilidade de aproveitamento dessas publicações pela quantidade de sugestões, exercícios e até de alguns conhecimentos artísticos de caráter amplo e geral. O que está em questão não é o "livro didático", mas o papel que desempenhou num momento em que o objetivo era subsidiar professores sem formação para o trabalho com arte.

Salvo algumas exceções, o enfoque tecnicista dessas publicações - ênfase nas atividades descoladas de fundamentos teóricos, instrução programada, uso de linguagem coloquial e bonecos ilustrativos - aponta para a infantilização dos alunos de $5^{\mathrm{a}}$ a $8^{\mathrm{a}}$ séries $^{9}$ e o reducionismo dos conhecimentos artísticos.

No próximo item, relata-se uma experiência de educação artística à luz dos determinantes da lei n. 5.692/71, mas que, contraditoriamente, ultrapassa a polivalência e afirma a especificidade das áreas artísticas.

Breve relato de uma experiência à luz dos fundamentos da lei

Na década de 1970, no estado do Paraná, O CETEPAR (Centro de Seleção e Aperfeiçoamento de Pessoal do Estado do Paraná) encampou o

9 A denominação $1^{\mathrm{a}}$ a $8^{\mathrm{a}}$ série e $2^{\circ}$ grau corresponde ao que hoje se denomina educação básica (educação infantil, ensino fundamental e ensino médio). 
processo de implantação da reforma de ensino e a Escolinha de Artes do Colégio Estadual do Paraná (CEP) ${ }^{10}$ em 1973, assumiu o papel de centro disseminador das experiências pedagógicas propostas pela lei n. 5.692/71. As atividades de arte, em contraturno, dos alunos de $5^{\mathrm{a}}$ a $8^{\mathrm{a}}$ séries, que pela manhã estudavam nas unidades-polo - escolas da região de abrangência do colégio -, constituíam-se de propostas de expressão sonora (música, som e ritmo); expressão bitridimensional (artes plásticas); expressão corporal (teatro); e expressão pela palavra (linguagem).

Cabe frisar uma contradição nessa experiência, quando eram apregoadas a comunicação e expressão e a polivalência para a educação artística. Apesar da integração de conteúdos através de projetos conjuntos, na Escolinha de Arte do CEP, cada área era trabalhada por um professor especialista em música, teatro e artes plásticas, além do professor de língua portuguesa; pelo menos nas $5^{\text {as }}$ e $6^{\text {as }}$ séries. Nesse sentido, há que se ressaltar o esforço desses professores em propor aos alunos conhecimentos significativos, apesar dos limites tecnicistas impostos ${ }^{11}$.

As atividades eram planejadas por intermédio da elaboração coletiva de projetos, na perspectiva da análise de sistemas, e seguia uma ordem: 1 Pré-plano - definição e análise do problema, levantamento de hipótese; 2 Plano - Objetivos (gerais e instrucionais), padrões mínimos por atividade, requisitos, especificações e cronograma.

Nas $5^{\text {as }}$ e $6^{\text {as }}$ séries, as atividades denominavam-se "Expressão" e cada professor trabalhava com objetivos próprios da sua área. Abaixo, exemplos de objetivos de um projeto denominado Interpress, planejado coletivamente por professores de cada área:

Objetivo geral: o aluno deverá expressar-se criativamente, demonstrando ter interiorizado os estímulos sensoriais apresentados.

10 Denominado, na época, de "Colégio Estadual do Paraná - Complexo Escolar de Ensino Regular e Supletivo de $1^{\circ}$ e $2^{\circ}$ graus".

11 A autora participou desse processo como professora de expressão sonora e educação artística e possui, em seu acervo pessoal, os projetos elaborados e aplicados na escolinha de artes e nas escolas que faziam parte do Complexo Escolar do Colégio Estadual do Paraná de 1974 a 1979. 
Objetivos instrucionais:

Expressão sonora: o aluno deverá apontar uma possibilidade rítmica e uma sonora, de um material determinado (isopor ou madeira) através do seu manuseio;

Expressão bi e tri dimensional: o aluno compõe um trabalho (bi ou tri dimensional) procurando equilíbrio, forma e tonalidade, com material determinado. (COLÉGIO..., 1974a, p. 2-3) ${ }^{12}$.

Nas $7^{a_{s}}$ e $8^{a_{s}}$ séries, a denominação era "Educação Artística", com um professor de qualquer das áreas e propostas de caráter geral. A seguir, exemplos de objetivos instrucionais do projeto denominado Arteci-Pro:

Objetivo geral: descobrir as interligações entre o desenvolvimento técnico-científico e arte-profissão.

Objetivos instrucionais: Enumerar dez manifestações de expressão da comunidade; Comparar em grupo técnica e material de 3 obras de arte, realizadas em épocas distintas; descrever, em relatório, a mão de obra e materiais necessários para a montagem de um filme/e, ou disco/e ou, peça teatral/e, ou programa de TV (COLÉGIO..., 1974b, p. 1-2).

Eram enfocadas as expressões culturais da comunidade e as possibilidades profissionais da arte, tendo em vista a faixa etária e o preconizado pela lei quanto à ênfase na preparação para o trabalho ao final do $1^{\circ}$ grau.

Assim se explicitou a transposição dos fundamentos metodológicos da lei em sua aplicação na prática escolar, pelo menos numa realidade situada e datada, conforme anunciamos acima.

Analisando esse processo com o devido distanciamento, é possível afirmar que, apesar do enfoque tecnicista, expressivo e dentro de uma perspectiva sistêmica que embasava toda a lei, a proposta efetivada na escolinha de artes foi importante, valendo ressaltar alguns pontos:

- Trabalho coletivo, planejamento avaliação, técnicas e instrumentos que objetivavam intervir na educação artística, de modo a propor experiências significativas em todas as áreas da arte;

12 As palavras e expressões grifadas são, respectivamente, o padrão mínimo e as condições de execução de cada objetivo. 
- Gestão e prática articuladas através de planejamento e intervenção nos aspectos materiais e pedagógicos sempre que necessário;

- Integração e tangenciamento das diferentes áreas artísticas, para além da polivalência "economicista" apregoada pela lei, já que havia professores com formação específica em música, teatro e artes plásticas.

É necessário acrescentar que tais condições decorrem das características próprias da Escolinha de Artes do Colégio Estadual do Paraná, instituição de relevância histórica no ensino paranaense. Isso provavelmente não ocorreu nos demais estabelecimentos de ensino.

O próximo item faz uma revisão crítica dos fundamentos teóricometodológicos da lei n. 5.692/71, que, em última instância, determinaram uma forma de encaminhamento da arte na escola.

\section{A necessária revisão crítica dos fundamentos e propósitos da lei n. 5.692/71}

Problematizar a extensiva e intensiva administração a que foi submetida a prática artística na escola requer uma compreensão teórica mais aprofundada. Nessa perspectiva, vale uma afirmação de Netto (1992, p. 34) quando diz que, nesse momento, a "dominação assume o caráter de administração".

Parece que essa administração da totalidade social cumpriu seu papel ao colocar a arte, seus conteúdos, metodologias e professores sob o predomínio das técnicas travestidas de "expressão", tornando-as, desta forma, obrigatórias na escola.

Nesse sentido, é pertinente trazer Chauí (1986, p. 64) que questiona o "ativismo transformista" e a "aplicação mecânica de modelos", dizendo que essa é uma abdicação da necessidade de pensar:

Dessa maneira, não é apenas o trabalho do pensamento que se perde, mas a própria idéia da ação com práxis social, uma vez que a atividade, longe de ser criação do possível histórico, se consome numa pura técnica de agir circunscrita ao campo do provável e do previsível. 
Na dimensão pedagógica da lei em seus princípios e efeitos intracurriculares, a organização do trabalho pedagógico em todos os seus aspectos obedece a alguns fundamentos, os quais vale a pena lembrar. Essa organização recoloca, com força de lei, uma determinada orientação que remete ao ensino intuitivo e ao primado dos sentidos: "Tudo deve ser realizado de acordo com a ordem da natureza cuja efetivação vai do mais simples e inferior para o mais amplo e mais elevado. Isto significa, do conhecido ao desconhecido [...]" (RATKE, 2008, p. 62 apud HOFF, 2008, p. 51).

Parra (1977, p. 18) ${ }^{13}$ justifica essa gradualização didática (das atividades para as disciplinas), destacando a gênese no método intuitivo, com base na experiência direta com o intercurso dos sentidos, apregoado por autores como Comenius, Pestalozzi e Herbart, entre outros:

Exercitem-se primeiro os sentidos das crianças (o que é muito fácil), depois a memória, a seguir Inteligência, e por fim o juízo. Todos esses exercícios devem ser feitos um após o outro, gradualmente, pois o saber começa a partir dos sentidos, e, através da imaginação passa para a memória, e depois, pela indução a partir das coisas singulares, chega à inteligência das coisas universais, e finalmente, acerca das coisas bem entendidas, emite o juízo, o que permite chegar à certeza da ciência (COMENIUS, s./d. apud PARRA, 1977, p. 19-20).

O autor afirma que, com o movimento escolanovista, há uma transição do método intuitivo para os métodos ativos da Escola Nova e critica a centralidade no professor na relação ensino aprendizagem presente nas abordagens tradicionais. Também apregoa:

[...] acreditamos encontrar no conceito de "atividade" o ponto comum de convergência de todos os que [...] estão envolvidos no processo renovador do ensino [...].. A inteligência procede da ação em seu conjunto, na medida em que transforma os objetos e o real, e que o conhecimento [...] é essencialmente, assimilação ativa e operatória (PARRA, 1977, p. 53).

13 Optamos por utilizar esse autor, em vez das formulações de Piaget no original, porque entendemos que Parra foi um dos autores que teorizou sobre a psicologia genética na aplicação desses fundamentos às interpretações da lei n. 5.692/71 para o ensino. Suas publicações foram apropriadas nos cursos de pedagogia, em especial nas disciplinas de caráter mais técnico como a de técnicas audiovisuais. 
É evidente a neutralidade da apropriação desses fundamentos, numa dimensão instrumental do conhecimento, vazia de um suporte histórico social. Não se questiona aqui a teoria piagetiana em si, analisa-se, no entanto, a sua apropriação enviesada nos encaminhamentos legais dessa época. Ora, assimilação ativa e operatória não significa necessariamente ênfase somente em experiências sensório-motoras e ativismo empírico.

Batista (2000, p. 194) aponta a submissão do sujeito ao conhecimento, no construtivismo de Piaget:

A construção do conhecimento, no entender de Piaget (1965), passa pela sujeição conceituada numa concepção biológica e não sócio-política. [...] $\mathrm{O}$ sujeito se constitui como tal a partir da sujeição da natureza ao pensar e agir matemáticos e do reducionismo que este procedimento implica. Contudo, a sujeição não se deu ao nível do objeto simplesmente, mas do sujeito que precisou e tem precisado se sujeitar a esse conhecimento para sobreviver.

A autora critica uma epistemologia que apregoa o desenvolvimento infantil como um processo natural, em "passos sucessivos", como condição para relações igualitárias. Sabe-se que isso não se aplica a todas as sociedades (BATISTA, 2000, p. 202). Particularmente, ao caso brasileiro naquele momento histórico.

Na verdade, os aportes teórico-metodológicos da lei n. 5.692/71 unem métodos intuitivos, livre expressão e tecnicismo. Esse "vale tudo" metodológico desconsidera a educação como fator de emancipação e demarca um papel para a escola, naquele momento, em função do controle e do desenvolvimento econômico.

Voltando os olhos ao passado, percebe-se que a ênfase em planejar, avaliar e sistematizar a arte na escola fez com que se escamoteasse uma característica que lhe é inerente: a possiblidade de lidar com o inusitado, com a crítica, com a reflexão sobre os processos e produtos artísticos e sobre a função humanizadora que a arte pode exercer na sociedade.

\section{Considerações finais}

Ao final, cabe refletir sobre a contradição inerente à promulgação da lei n. 5.692/71 no que se refere à arte, pois, mesmo não concordando 
com seus fundamentos, ressalte-se a coerência interna da argumentação teórico-metodológica, a sistematização e a gestão de ações de modo a adequar a realidade do ensino de arte (ou o que quer que se entendesse por arte) nas escolas às concepções da lei.

Assim, de um lado, a obrigatoriedade colocou de forma indiscutível a prática artística no currículo e essa disciplina tem, desde então, espaço garantido por lei na escola. De outro, a polivalência e a ênfase na expressão e comunicação obliteraram a função precípua da arte, que é humanizar os sujeitos por meio de experiências estéticas significativas, de leituras críticas e criativas da realidade, tendo como mediação nesse processo os conhecimentos e conteúdos específicos da arte em suas diferentes manifestações.

Cabe reforçar o entendimento de que essa função tem como corolário a formação de professores devidamente habilitados em cada área específica dança, teatro, música, artes visuais -, mas sem perder de vista os conteúdos artísticos mais abrangentes em sua constituição como campo de conhecimento: relação sujeito-objeto na arte, funções da arte na sociedade e história da arte como trabalho criador .

Pode-se afirmar que o ensino de arte nas escolas ainda hoje reflete as determinações metodológicas da educação artística, tendo como pressuposto a polivalência e a hegemonia das artes plásticas pela afirmação da arte-educação desde a década de 1970. Stori (2011), em sua pesquisa, detectou a exigência da maioria dos gestores, numa dada realidade, da atuação polivalente dos professores que, com ou sem formação para isso, devem propor atividades de todas as áreas num curto espaço de tempo.

Parece evidenciar-se também que, no geral, a arte na escola, apesar das injunções legais e dos movimentos afirmativos das entidades específicas ${ }^{14}$, é ainda tributária de uma concepção utilitarista dos conhecimentos escolares, privilegiando os saberes demandados pela sociedade capitalista e de mercado. Sebben (2009) constatou em sua pesquisa que, nas escolas particulares, os alunos consideravam desnecessário o ensino de música, uma vez que este não afere conhecimentos requeridos pelo vestibular e pelo mercado de trabalho.

No sentido do movimento dialético - conservação/mudança -, Mészáros (2005, p. 47) questiona a possibilidade de transformação da educação

14 Associação Brasileira de Educação Musical (ABEM) e Federação de Arte Educadores do Brasil (FAEB). 
no atual estado de coisas. Isso só seria possível quando fosse superado o modo de produção capitalista. O autor afirma, parafraseando Marx, que o escopo da aprendizagem é a autorrealização dos homens como "indivíduos socialmente ricos humanamente". No entanto, o autor acrescenta que, para além da sociedade capitalista, é preciso pensar na sociedade democrática tendo como horizonte a emancipação humana.

A utopia, ao buscar conhecer o quanto do passado permanece no presente, é contribuir com a problematização desse campo, de modo a propor as mudanças necessárias para que as práticas artísticas assumam seu caráter emancipador e humanizador nesta sociedade, com as crianças, jovens e adultos que hoje frequentam as escolas como alunos e como professores.

\section{Referências}

Abrahão, Luz Martins. Música comunicação. São Paulo: Companhia Editora Nacional, [s./d.]. Edição do professor, v. 2.

ABrahão, Luz Martins et al. Integrando as artes. São Paulo: Companhia Editora Nacional, 1977.

Barbosa, Ana. Mae. Arte-educação: conflitos e acertos. 2. ed. São Paulo: Max Limonad, 1985.

Batista, Soely Soares dos Santos. Teoria Critica e teorias educacionais: Uma análise do discurso sobre educação. Educação \& Sociedade, São Paulo, v. 21, n. 73 , p. 182-204, dez. 2000.

Brasil. Ministério da Educação e Cultura. Lei no 5.692, de 11 de agosto de 1971. Fixa diretrizes e bases para o ensino de $1^{\circ}$ e $2^{\circ}$ graus, e dá outras providências. Diário Oficial da República Federativa do Brasil, Brasília, DF, 12 ago. 1971. Seção 1.

Ministério da Educação e do Desporto. Lei n ${ }^{0}$ 9.394, de 20 de dezembro de 1996. Lei de Diretrizes e Bases da Educação Nacional. Diário Oficial da República Federativa do Brasil, Brasília, DF, dez. 1996. Disponível em: <http:// www.planalto.gov.br/ccivil/LEIS/L9394.htm>. Acesso em: 25 out. 2011.

. Ministério da Educação. Lei no 11.769/08, de 18 de agosto de 2008. Altera a Lei ${ }^{\circ}$ 9.394, de 20 de dezembro de 1996, Lei de Diretrizes e Bases da Educação, 
para dispor sobre a obrigatoriedade do ensino de música na educação básica. Diário Oficial da República Federativa do Brasil, Brasília, DF, 19 ago. 2008. Disponível em: <http://www.planalto.gov.br/ccivil_03/_Ato2007-2010/2008/Lei/L11769. htm>. Acesso em: 15 jul. 2011.

Canclini, Néstor García. A socialização da arte - teoria e prática na América Latina. 2. ed. São Paulo: Cultrix, 1984.

Chauí, Marilena de Souza. O que é ser educador hoje? Da arte à ciência: a morte do educador. In: BRANDÃo, Carlos Rodrigues et al. O educador: vida e morte - escritos sobre uma espécie em perigo. 8. ed. Rio de Janeiro: Edições Graal, 1986.

Chervel, André. História das disciplinas escolares: reflexões sobre um campo de pesquisa. Teoria e Educação, Porto Alegre, n. 2, p. 177-229, 1990.

Colégio Estadual do Paraná - CEP. Projeto INTER-PRES. $\sigma^{a}$ série. Curitiba: CEP, 1974a. Não publicado.

. Projeto ARTECI-PRO. $7^{a}$ Série. Curitiba: CEP, 1974b. Não publicado.

Cotrim, Gilberto. Educação Artística: expressão corporal - musical - plástica - $1^{\circ}$ grau. São Paulo: Saraiva, 1978. v. 1.

Fleitas, Ornaldo. Comunicação pela arte - Educação Artística: $6^{\text {a }}$ Série. São Paulo: Editora FTD, 1977.

ForQuin, Jean Claude. Saberes escolares, imperativos didáticos e dinâmicas sociais. Teoria e Educação, Porto Alegre, n. 5, p. 28-49, 1992.

Herling, André. Caderno de Desenho e Educação Artística. São Paulo: Instituto Brasileiro de Edições Pedagógicas - IBEP, [s./d.].

Hoff, Sandino. O pensamento burguês na organização do trabalho didático moderno. Práxis Educativa, Ponta Grossa, v. 3, n. 1, p. 43-54, jan./jun. 2008.

MaiA, Maria. Villa Lobos Alma Brasileira. Rio de Janeiro: Contraponto, Petrobrás, 2000.

McLuhan, Marshal. Os meios de comunicação como extensões do homem. 5. ed. São Paulo: Cultrix, 1989.

McLuhan, Marshal; Fiore, Quentin. The Medium is the Massage: An Inventory of Effects. New York: Bantam Books, 1967. 
Mészáros, István. A educação para além do capital. São Paulo: Boitempo, 2005.

Netto, José Paulo. Capitalismo monopolista e serviço social. São Paulo: Cortez, 1992.

Paraná. Secretaria de Estado da Educação. Proposta Preliminar de Educação Artística - $2^{\circ}$ Grau. Curitiba, 1988.

.Secretaria de Estado da Educação. Currículo Básico para a Escola Pública do Paraná. Curitiba, 1990.

Parra, Nélio. Metodologia dos recursos audiovisuais: estudo fundamentado na psicologia genética de Jean Piaget. 2. ed. São Paulo: Saraiva, 1977.

Penteado, José de Arruda. Comunicação visual e expressão - artes plásticas e desenho $1^{\circ}$ e $2^{\circ} \mathrm{Grau}$. São Paulo: Companhia Editora Nacional, 1977. v. 1.

Revista Brasileira de Estudos Pedagógicos. Rio de Janeiro: MeC/INEP, v. 59, n. 132, p. 569-760, out./dez. 1973.

Rio de Janeiro. Secretaria Municipal de Educação e Cultura-Comunicação e expressão. Educação artística. Niterói: Imprensa Oficial do Estado do Rio de Janeiro, 1977a.

. Arte na escola de $1^{\circ}$ grau. Niterói: Imprensa Oficial do Estado do Rio de Janeiro, 1977b.

SAVIAnI, Dermeval. A nova lei da educação - LDB trajetória limites e perspectivas. 2. ed. Campinas: Editores Autores Associados, 1997.

SEbBen, Egon Eduardo. Concepções e práticas de música na escola na visão de alunos de $8^{a}$ série do ensino fundamental: as contradições entre o legal e o real. 2009. 167 f. Dissertação (Mestrado em Educação)-Universidade Estadual de Ponta Grossa, Ponta Grossa, 2009.

SouZa JúnIor, Marcílio; Galvão, Ana Maria de Oliveira. História das disciplinas escolares e história da educação: algumas reflexões. Educação e Pesquisa, São Paulo, v. 31, n. 3, p. 391-408, set./dez. 2005.

Stori, Regina. As Diretrizes Curriculares de Arte do Estado do Paraná: uma análise dos fundamentos e da gestão do ensino de música em Ponta Grossa/PR (2003-2010). 2011. 190 f. Dissertação (Mestrado em Educação)-Universidade Estadual de Ponta Grossa, Ponta Grossa, 2011. 
Subtil, Maria José Dozza. Educação e arte: dilemas da prática que a história pode explicar. Revista Práxis Educativa, Ponta Grossa, v. 4, n. 2, p. 185-194, jul./dez. 2009a. Disponível em: <http://www.revistas2.uepg.br/index.php/ praxiseducativa/issue/current>. Acesso em: 25 maio 2010.

. Uma contribuição ao estudo da educação musical nas políticas públicas brasileiras: educação artística, expressão e polivalência na Lei 5.692/71. In: CONGRESSO NACIONAL DA ASSOCIAÇÃO BRASILEIRA DE EDUCAÇÃO MUSICAL, 18., 2009, Londrina. Anais... Londrina: Universidade Estadual de Londrina, 2009b. p. 1231-1237.

. Reflexões sobre ensino de arte: Recortes históricos sobre políticas e concepções. Revista do HISTEDBR, Campinas, n. 41, p. 241-254, maio 2011.

Endereço para correspondência:

Maria José Dozza Subtil

Rua Centauro, 120

Colônia Dona Luiza

Ponta Grossa - PR

CEP: 84043-555

E-mail:mjsubtil@hotmail.com

Recebido em: 14 out. 2011

Aprovado em: 10 jul. 2012 
